\title{
The International Journal of Emergency Medicine: successes of the first year
}

\author{
Latha G. Stead • Wyatt W. Decker
}

Received: 5 March 2009 /Accepted: 5 March 2009/Published online: 15 April 2009

(C) Springer-Verlag London Ltd 2009

When the first call for papers for the International Journal of Emergency Medicine (IJEM) went out in January 2008, all of us believed in the journal, few of us knew how the EM fraternity would respond, and none of us could predict its status one year later. A year has now passed, 4 issues down the road, and we are privileged to report on its successes. These have been multi-factorial: a dedicated cadre of peer reviewers, a loyal editorial board, a supportive publishing team, and, perhaps most importantly, a real need for such a journal to exist.

We all have been through the anguish as the author of an article awaiting journal reviews. IJEM has striven to ensure a quick turnaround time for the manuscripts received. The journal turnaround time includes several components. The average number of days between the date the manuscript

Journal statistics: As of January 2009, IJEM had received a total of 181 submissions, in the following categories, with an acceptance rate of $52 \%$.

Original Article (research)

Brief Research Report

Clinical Images

State of International EM

Innovations in EM Practice

Review Article

Case Report

Editorial

Clinical Research Capsule

Letter to the Editor

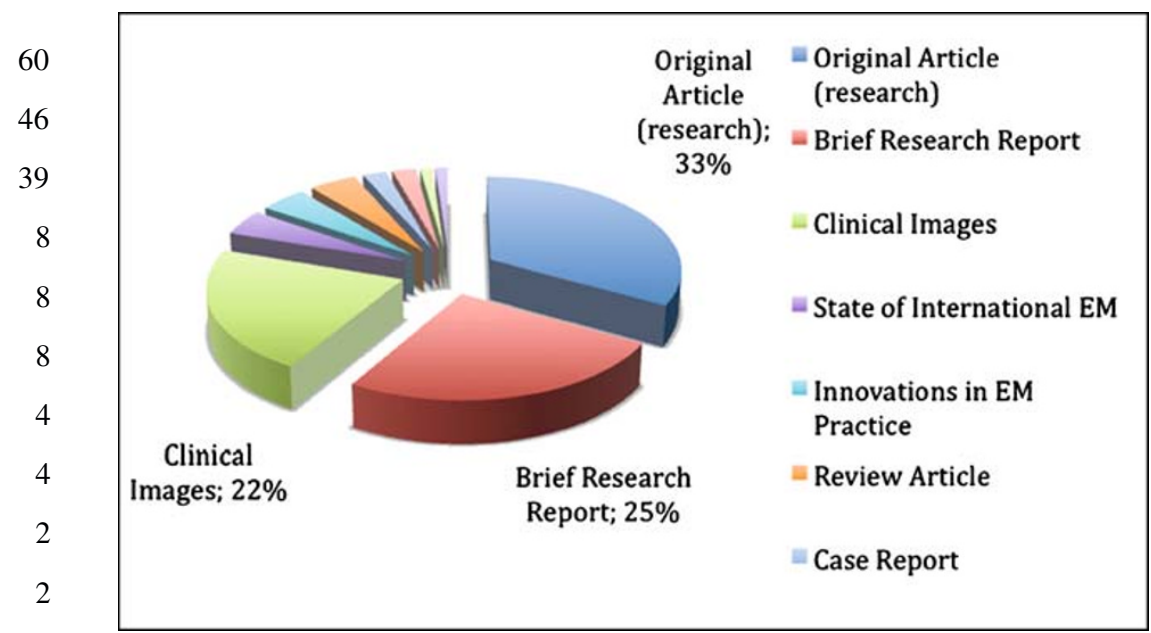

\section{G. Stead $(\square)$}

Department of Emergency Medicine,

University of Rochester School of Medicine and Dentistry,

Rochester, NY, USA

e-mail: latha_stead@urmc.rochester.edu

W. W. Decker

Department of Emergency Medicine,

Mayo Clinic College of Medicine,

Rochester, MN, USA

e-mail: decker.wyatt@mayo.edu was received and the first editor was assigned was 0.9; in other words, most manuscripts were assigned the same day they arrived at Editorial Manager. The average time between the date the manuscript was received and the first reviewer was invited was 4.2 days. This is a number that reflects our initial start up time in assigning the fields of expertise for each reviewer, and the time lag to upload reviewer data. In the last month, papers arriving at Editorial Manager have been assigned to a reviewer within 48 hours. 
The average period between the date the manuscript was received and the first decision (accept, accept with minor/ major revisions, or reject) was 20.2 days. This is an important statistic as IJEM recognizes the value of its contributors' works and the need to disseminate the knowledge as expeditiously as possible. We continue to strive towards fast turnaround times.

The breadth of the submissions in terms of country of origin continues to expand. In the first year of the journal, we had submissions from 30 countries: Argentina, Australia, Canada, People's Republic of China, Colombia, Germany, Greece, India, Israel, Italy, Jamaica, Japan, South Korea, Malaysia, Nepal, Netherlands, New Zealand, Pakistan, Saudi Arabia, Singapore, Slovenia, South Africa, Spain, Taiwan, Thailand, Turkey, Uganda, UK, USA, and Vietnam. This is gratifying, because one of the aims in starting IJEM was to engage the international emergency medicine community. Historically, authors from countries outside of the USA have had difficulty getting their work published. Indeed, fewer than $8 \%$ of published articles in the major EM journals are from authors outside the USA. IJEM, however, recognizes the need for international EM work to be disseminated, and this first year underscores the wealth of information that needs to be brought to light. All articles in 2009 continue to be free open access, with no charge to authors for publishing and no charge for readers to download full text content.

Just 12 months after its launch, IJEM is now indexed in Pubmed Central as well as Scopus! Articles are retroactively indexed back to the first issue, and can be accessed at: http:// www.pubmedcentral.nih.gov/tocrender.fcgi?journal $=594 \&$ action=archive. As the Journal is an Open Access title inclusion in PMC means that it will also be indexed in PubMed/Medline as well. We have indeed been fortunate to receive high quality research and practice papers that have led to this milestone.

With the increasing volume of manuscripts pouring in, IJEM welcomes Dr. Anunaya R. Jain as managing editor.
Dr. Jain is an instructor of Emergency Medicine at the Mayo Clinic College of Medicine and will oversee the IJEM peer review process and turnaround times.

IJEM would like to thank all of its reviewers for their selfless dedication to the work of the journal. IJEM is further pleased to award the 2008 Outstanding Peer Reviewer Awards to the following reviewers:

- Jana Anderson, MD

- Amado Alejandro Báez, MD, MPH

- M.Fernanda Bellolio, MD

- Colin A Graham, M.D., M.P.H.

- Sigrid A. Hahn, MD

- Anunaya Jain, M.B.B.S, MCEM

- David Nestler, MD

- Christopher Scott Russi, DO

- Leon D. Sanchez, MD, MPH

- Chew Keng Sheng, M.D, MMed

- Matt Sztajnkrycer, MD, PhD

Starting with volume 2 issue 3 , IJEM is pleased to introduce a new journal feature entitled "Video Innovations in Emergency Medicine," which will be led by new editorial board member Dr. S. V. Mahadevan. Dr. Mahadevan is an associate professor of emergency medicine at Stanford University in Palo Alto, California. He has a wealth of experience in multimedia, and has published an award winning emergency medicine textbook. Watch for this new feature in upcoming issues.

IJEM also welcomes new editorial board members Dr. Jonathan Edlow, Associate Chief at Beth Israel Deaconess Medical Center, Harvard Medical School in Boston, Massachusetts, and Dr. John McCabe, Chair at Upstate Medical Center in Syracuse, New York.

We thank all of you for reading and writing to IJEM and making it a success.

Welcome to an exciting new year of the International Journal of Emergency Medicine. 